\title{
Rapid Screening for Japanese Dysferlinopathy by Fluorescent Primer Extension
}

\author{
Saori Hayashi ${ }^{1}$, Yutaka Ohsawa ${ }^{1}$, Toshiaki Takahashi ${ }^{2}$, Naoki Suzuki $^{3}$, Tadashi Okada ${ }^{1}$, \\ Mitsue Rikimaru ${ }^{1}$, Tatsufumi Murakami ${ }^{1}$, Masashi Aoki ${ }^{3}$ and Yoshihide Sunada ${ }^{1}$
}

\begin{abstract}
Objective Mutations in the dysferlin gene cause limb-girdle muscular dystrophy (LGMD) 2B and Miyoshi myopathy (MM), which are collectively named dysferlinopathy. Dysferlinopathy is the most frequent type of LGMD in the Japanese population. Molecular genetic analysis is essential for the diagnosis of dysferlinopathy because of its variable immunohistochemical patterns of biopsied muscles, including patterns similar to normal controls. The analysis of the entire dysferlin gene however, is time-consuming and laborious; therefore a simple and rapid screening method to detect hot spot mutations in the dysferlin gene is essential for the diagnosis of dysferlinopathy.

Methods We previously showed that 4 mutations, c. $937+1 \mathrm{G}>\mathrm{A}, \mathrm{c} .1566 \mathrm{C}>\mathrm{G}, \mathrm{c} .2997 \mathrm{G}>\mathrm{T}$ and c. $3373 \mathrm{delG}$ account for $50 \%$ of all the mutations identified in Japanese dysferlinopathy patients. We performed a onetube multiplex PCR, followed by extension of primers for each mutation with a fluorescence-labeled dideoxynucleotide to screen the 4 hot spot mutations.

Results The multiplex primer-extension reaction was developed on samples of known mutations. The extension products were represented as 4 different peaks that corresponded to a mutated nucleotide on electropherogram. Using the developed screening method, we were able to detect mutations in these hot spots in 3 samples out of 8 clinically suspected LGMD2B/MM patients in only approximately 8 hours. These 3 cases were definitely diagnosed as LGMD2B/MM by exonic sequencing.

Conclusion We have developed a simple and rapid screening method which could facilitate the definitive diagnosis of dysferlinopathy, contributing to an understanding of the genotype-phenotype correlations for dysferlinopathy.
\end{abstract}

Key words: limb-girdle muscular dystrophy (LGMD) 2B, Miyoshi myopathy (MM), dysferlinopathy, mutational hot spots, fluorescent primer extension

(Intern Med 49: 2693-2696, 2010)

(DOI: 10.2169/internalmedicine.49.3771)

\section{Introduction}

The loss of dysferlin, resulting from homozygous or compound heterozygous mutations in the dysferlin gene (GeneID: 8291) causes dysferlinopathy, including autosomal recessive limb-girdle muscular dystrophy (LGMD) 2B, Miyoshi myopathy (MM) and distal anterior compartment myopathy $(1,2)$. Dysferlinopathy is the most frequent type of LGMD in the Japanese population (personal communica- tion by Dr. Yukiko Hayashi, National Center of Neurology and Psychiatry). Commonly, the diagnosis of dysferlinopathy is made by immunohistochemistry (IHC). However, IHC analyses with anti-dysferlin antibodies in LGMD2B/MM patients show multiple staining patterns, including patterns similar to normal controls. In addition, other types of LGMD, such as LGMD2A and LGMD1C sometimes show altered immunostaining patterns similar to LGMD2B/ MM (3). Therefore, molecular genetic analysis is essential for the diagnosis of dysferlinopathy. Because the dysferlin

${ }^{1}$ Department of Neurology, Kawasaki Medical School, Kurashiki, ${ }^{2}$ Department of Neurology, Nishitaga National Hospital, Sendai and ${ }^{3}$ Department of Neurology, Tohoku University School of Medicine, Sendai

Received for publication April 7, 2010; Accepted for publication August 26, 2010

Correspondence to Dr. Yoshihide Sunada, ysunada@med.kawasaki-m.ac.jp 
Table 1. Clinical Features of 10 Patients

\begin{tabular}{|c|c|c|c|c|c|}
\hline $\begin{array}{l}\text { Patient } \\
\text { No. }\end{array}$ & Sex & $\begin{array}{l}\text { Age at } \\
\text { onset, } y\end{array}$ & Clinical diagnosis & $\begin{array}{l}\text { Hot spot mutations by } \\
\text { primer extension }\end{array}$ & $\begin{array}{l}\text { Other mutations by } \\
\text { exonic sequencing }\end{array}$ \\
\hline 1 & $\mathrm{~F}$ & 21 & LGMD2B & c. $2997 \mathrm{G}>\mathrm{T}+\mathrm{c} .2997 \mathrm{G}>\mathrm{T}$ & - \\
\hline 2 & M & 56 & LGMD2B* & - & ND \\
\hline 3 & M & 18 & LGMD2B* & 一 & ND \\
\hline 4 & $\mathrm{M}$ & 15 & MM & c. $1566 \mathrm{C}>\mathrm{G}$ & c. $265 \mathrm{C}>\mathrm{T}$ \\
\hline 5 & $\mathrm{~F}$ & 56 & $\mathrm{MM}^{*}$ & 一 & ND \\
\hline 6 & $\mathrm{~F}$ & 66 & $\mathrm{MM}^{* *}$ & - & ND \\
\hline 7 & M & 18 & MM & 一 & c. $3112 \mathrm{C}>\mathrm{T}+$ c. $5226 \mathrm{C}>\mathrm{T}$ \\
\hline 8 & M & 15 & MM & c.3373delG & c. $1321 \mathrm{C}>\mathrm{T}$ \\
\hline 9 & M & 60 & other LGMD & - & ND \\
\hline 10 & $\mathrm{~F}$ & 21 & other LGMD & 一 & ND \\
\hline
\end{tabular}

ND: not determined. Dysferlin immunoreactivity: *absent, **faint.

Table 2. Primers Used for PCR and Extension Reaction

\begin{tabular}{|c|c|c|}
\hline $\begin{array}{l}\text { Mutations } \\
\text { (No. of Exon) }\end{array}$ & Primer sequences & Size Bp \\
\hline \multirow{3}{*}{$\begin{array}{l}\text { c. } 937+1 \mathrm{G}>\mathrm{A} \\
(\text { Exon } 10)\end{array}$} & F-ccacactttatttaacgetttggcgg & \multirow{4}{*}{19} \\
\hline & R-cagaaccaaaatgcaaggatacgg & \\
\hline & E-accatttacagagagcccc & \\
\hline \multirow{3}{*}{$\begin{array}{l}\text { c. } 1566 C>G \\
\text { (Exon 18) }\end{array}$} & F-cgacccetctgattgccacttgtg & \\
\hline & R-ggcatcctgccettgccaggg & \multirow[b]{2}{*}{24} \\
\hline & E-aaaaaccacttttgggccctgcta & \\
\hline \multirow{3}{*}{$\begin{array}{l}\text { c. } 2997 \mathrm{G}>\mathrm{T} \\
(\text { Exon } 28)\end{array}$} & F-tcctctcattgcttgectgttcgg & \multirow{4}{*}{28} \\
\hline & R-ttgagagcttgccggggatgg & \\
\hline & E-aaaaaaaaaagtgggaagatgaggaatg & \\
\hline \multirow{3}{*}{$\begin{array}{l}\text { c.3373delG } \\
\text { (Exon 31) }\end{array}$} & F-atctaactctctgggctagtc & \\
\hline & R-tatcaccccatagaggcctcgaag & \\
\hline & E-aaaaaaaaaaagcgtgatggatgacaagagt & 32 \\
\hline
\end{tabular}

F: Forward primer for exonic PCR, R: Reverse primer for exonic PCR,

E: Extension primer

gene consists of 55 exons spanning more than $150 \mathrm{~kb}$, molecular genetic analysis of the entire gene is time-consuming and laborious. Therefore, an easier method to screen for common mutations is now required to facilitate DNA-based diagnosis of dysferlinopathy. We previously showed that 4 mutations, c. $937+1 \mathrm{G}>\mathrm{A}, \quad$ c. $1566 \mathrm{C}>\mathrm{G}, \quad$ c. $2997 \mathrm{G}>\mathrm{T}$ and c. $3373 \mathrm{delG}$ account for $50 \%$ of all the mutations identified in Japanese dysferlinopathy patients (4). In this study, we have developed a simple and rapid screening method to detect these mutational hot spots in the dysferlin gene using fluorescent primer extension.

\section{Materials and Methods}

\section{DNA samples}

To develop a new screening method, we collected control DNA samples from patients genetically diagnosed with dysferlinopathy. Genomic DNAs from patients with MM (n=8), carrying the homozygous and heterozygous mutations at the hot spots c. $937+1 \mathrm{G}>\mathrm{A}, \quad$ c. $1566 \mathrm{C}>\mathrm{G}, \quad$ c. $2997 \mathrm{G}>\mathrm{T}$, and c.3373delG in the dysferlin gene were used as positive controls, and 4 negative controls were applied to this study. Description of sequence variations are modified basically as recommended by the Ad-Hoc Committee for Mutation Nomenclature (AHCMN), with the recently suggested additions as follows; G1310A to c.937+1G $>\mathrm{A}$ (p.?), C1939G to c.1566C $>$ G (p.Y522X), G3370T to c.2997G $>$ T (p.W999C), and 3746delG to c.3373delG (p.E1125KfsX1134) (5).

To test the usefulness of the newly developed method, we further collected 8 DNA samples from patients who were clinically suspected to have LGMD2B/MM based on the typical clinical picture and the muscle biopsy finding of dysferlin deficiency and 2 other LGMD patients as shown in Table 1.

\section{PCR}

Pairs of primers were designed to amplify DNA fragments containing the 4 mutational hot spots (Table 2). Multiplex PCR amplification was performed in 1 tube, with 35 cycles of $94^{\circ} \mathrm{C}$ for 15 second, $55^{\circ} \mathrm{C}$ for 30 second and $72^{\circ} \mathrm{C}$ for 1 minute. The resulting PCR products were purified using a PCR purification kit (Qiagen, Hilden, Germany).

\section{Fluorescent primer-extension}

Using purified PCR products as the template, multiplex primer-extension reactions were performed in 1 tube to detect hot spot mutations using a SNaPshot ${ }^{\mathrm{TM}}$ Multiplex Kit (Applied Biosystems, Foster City, CA). We designed nonlabeled extension primers to anneal just $5^{\prime}$ of the mutated nucleotide. The primer length was altered by adding poly (dA) tails at the $5^{\prime}$ end to vary the size of the extension products (Table 2). Once the primer anneals, a single-base extension occurs by the addition of a complementary dideoxyribonucleoside triphosphate (ddNTP) to the $3^{\prime}$ end of the annealed primer. In the present study, the 4 ddNTPs were fluorescently labeled as follows: black for $\mathrm{G}$, green for $\mathrm{A}$, blue for $\mathrm{C}$ and red for $\mathrm{T}$. The primer extension reaction was performed in a final volume of $10 \mu \mathrm{L}$, containing $3 \mu \mathrm{L}$ of 
ttcattttcttttcatgtagtatcaaatgttgactgcctgtgtttccaaatgttcttcaaaaacatggtttttaatggaat

catataatgcaccacactttatttaacgctttggcggcaagagtttgatttgtgtctcctctcattgattgcagatg

gacgtgggcaccatttacagagagccc[G/A]tgagttctcaccactttggccgtatccttgcattttggtt

ctggaggctgattggggacactcatttggggtcctcactgtccctcctgggggttttagaatctagaggaagg

Figure 1. Sequence of exon 10 from the dysferlin gene containing the c.937+1G $>$ A mutation. Location of the forward primer and reverse primer (underlined) in relation to the extension primer (bold).

c. $937+1 \mathrm{G}>\mathrm{A}$
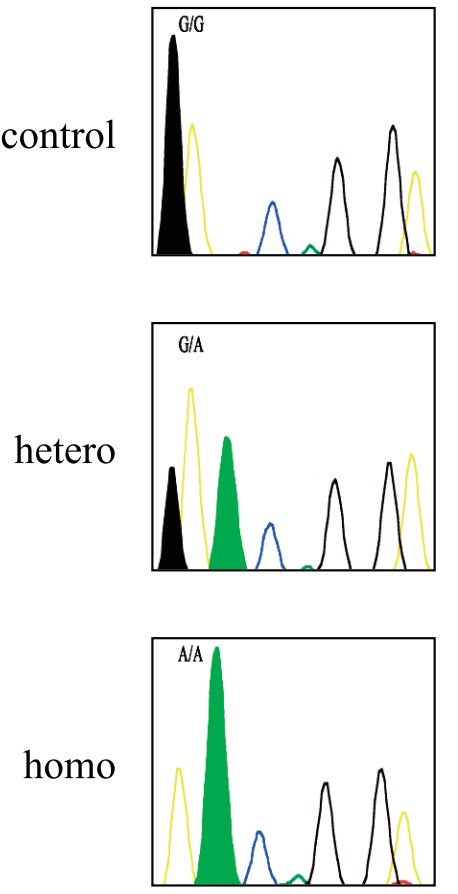

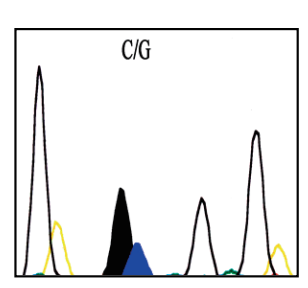

c. $1566 \mathrm{C}>\mathrm{G}$
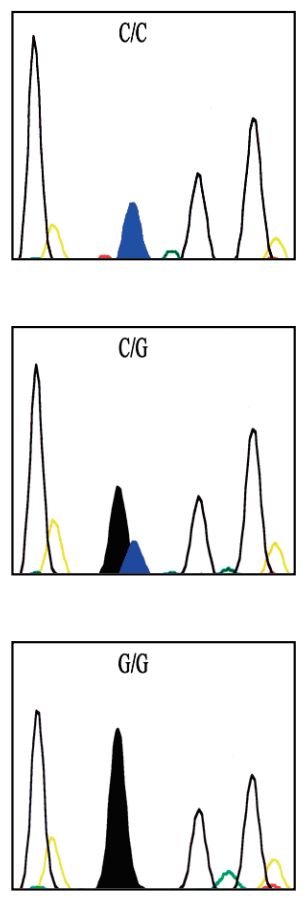

c. $2997 \mathrm{G}>\mathrm{T}$


c.3373delG
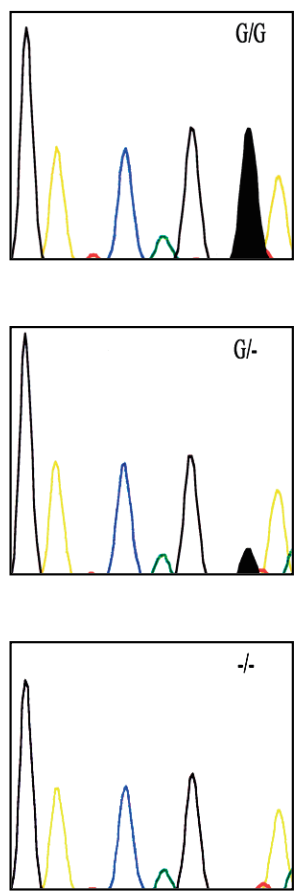

Figure 2. GeneScan electropherograms of the fluorescent primer extension reactions showing the 4 common mutations, c.937+1G $>$ A, c.1566C $>$ G, c.2997G $>$ T and c.3373delG. Each genotype was determined by both the position of the peak as well as by the color of the emitted fluorescence. Hetero, heterozygous mutation; homo, homozygous mutation.

PCR product (5 ng), $5 \mu \mathrm{L}$ of $\mathrm{SNaPshot}$ ready reaction mix (ddNTP terminators, DNA polymerase) and $0.2 \mu \mathrm{M}$ of each of the extension primers corresponding to the 4 hot spots. The cycling conditions were 25 cycles of $96^{\circ} \mathrm{C}$ for 10 second, $50^{\circ} \mathrm{C}$ for 5 second and $60^{\circ} \mathrm{C}$ for 30 second. Postextension treatment was conducted with 1 unit of calf intestinal alkaline phosphatase (Roche Molecular Biochemicals, Penzberg, Germany) for 60 minute at $37^{\circ} \mathrm{C}$, followed by 15 minute at $75^{\circ} \mathrm{C}$ for enzyme inactivation. The samples were subjected to capillary electrophoresis on an ABI 310 Genetic Analyzer (Applied Biosystems) and analyzed using GeneScan software (version 3.1, Applied Biosystems).

\section{Results}

Pairs of primers for exonic PCR were designed to flank the mutated nucleotide, and the extension primers were designed to end 1 nucleotide $5^{\prime}$ of the mutated nuceotide as shown in Fig. 1. Electropherograms of the PCR samples after single nucleotide primer extension at the 4 hot spot mutations are shown in Fig. 2. The extension products are represented as 4 different peaks that were determined by the primer length and the incorporated fluorescently labeled ddNTP. For the c. $937+1 \mathrm{G}>\mathrm{A}$ mutation, the control sample produced a black peak $(\mathrm{G})$, the homozygous mutant sample produced a green peak (A), and the heterozygous sample produced a black and a green peak ( $\mathrm{G}$ and $\mathrm{A})$. As expected, cases of c. $1566 \mathrm{C}>\mathrm{G}$ and c.2997G $>\mathrm{T}$ mutation were also fluorescence detected and interpreted on the electropherograms. In the case of the c.3373delG mutation, the control sample produced a black peak $(\mathrm{G})$, whereas the homozygous sample showed no peak, and the heterozygous sample pro- 
duced a smaller peak compared with the control sample. Direct sequencing was performed on these samples to verify the results of the fluorescent primer extension, and there was a complete concordance. The time required for the procedure was approximately 8 hour. Using the developed method, we actually screened the gene for mutations in 8 Japanese patients clinically suspected to have LGMD2B/ MM and 2 other LGMD patients (Table 1). We identified 1 homozygous mutation, c.2997G $>$ T (No.1) and 2 heterozygous mutations, c.1566C $>\mathrm{G}$ (No.4) and c.3373delG (No.8, total 4 alleles), out of 8 DNA samples from LGMD2B/MM patients (No.1-8, total 16 alleles). We further analyzed screening-negative alleles by exonic PCR and subsequent direct sequencing analyses. We detected mutations other than the 4 hot spots in the 2 heterozygous cases (No.4, 8) and confirmed the diagnosis of dysferlinopathy. One screening negative case (No.7) was diagnosed as dysferlinopathy by exonic sequencing alone. No mutations were detected in 2 DNA samples from other LGMD (No.9, 10) by the developed method.

\section{Discussion}

In this study, we developed a simple and rapid mutational screening method, in which both the genomic PCR and the primer extension reaction are multiplexed, and which takes only approximately 8 hour to detect mutations at any of the 4 Japanese LGMD2B/MM mutational hot spots in the dysferlin gene. This method is readily available for many laboratories, is easy to use and is suitable for a great many clinical samples. The design is flexible and more mutation sites could be added to the multiplex reactions.

Over the past 9 years, we have performed SSCP analysis of each exon of the dysferlin gene in over 150 samples from Japanese patients with clinically diagnosed or suspected LGMD2B/MM. Among them, we detected 28 different mutations in the coding region of the dysferlin gene, which were widely distributed along the entire length of the gene (unpublished data). However, using our newly developed screening method, we easily detected mutations at hot spots in 4 alleles out of 16 alleles in clinically suspected LGMD2 $\mathrm{B} / \mathrm{MM}$ patients. By analyzing more samples, the sensitivity and specificity of our new method will be determined.

We propose that our rapid screening method could be applied initially to the genomic screening for dysferlinopathy, which could detect up to $50 \%$ of the mutations in Japanese dysferlinopathy patients. Further, precise analyses by SSCP, gene chip or other mutation detection methods will be necessary only in the screening-negative cases. This novel screening method could facilitate the definitive diagnosis of dysferlinopathy, thereby contributing to an understanding of the genotype-phenotype correlations for this disease.

\section{Acknowledgement}

We thank Dr. Katsuhito Adachi for providing us with information and DNA samples. This work was supported by a research grant for Nervous and Mental Disorders from the Ministry of Health, Labor and Welfare (20B-13), and by research project grants from Kawasaki Medical School (20-602 and 20-604).

\section{References}

1. Liu J, Aoki M, Illa I, et al. Dysferlin, a novel skeletal muscle gene, is mutated in Miyoshi myopathy and limb girdle muscular dystrophy. Nat Genet 20: 31-36, 1998.

2. Illa I, Serrano-Munuera C, Gallardo E, et al. Distal anterior compartment myopathy: a dysferlin mutation causing a new muscular dystrophy phenotype. Ann Neurol 49: 130-134, 2001.

3. Tagawa K, Ogawa M, Kawabe K, et al. Protein and gene analyses of dysferlinopathy in a large group of Japanese muscular dystrophy patients. J Neurol Sci 211: 23-28, 2003.

4. Takahashi T, Aoki M, Tateyama M, et al. Dysferlin mutations in Japanese Miyoshi myopathy: relationship to phenotype. Neurology 60: 1799-1804, 2003.

5. den Dunnen JT, Antonarakis SE. Mutation nomenclature extensions and suggestions to describe complex mutations: a discussion. Hum Mutat 15: 7-12, 2000.

\footnotetext{
(C) 2010 The Japanese Society of Internal Medicine http://www.naika.or.jp/imindex.html
} 